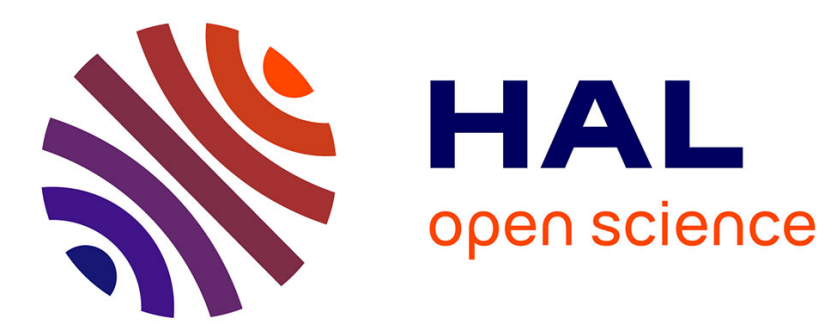

\title{
Modelling the impact of electrode roughness on net charge density in polyethylene
}

Mai Quyen Hoang, Man Quan Nguyen, Thi Thu Nga Vu, G. Teyssedre, Séverine Le Roy

\section{- To cite this version:}

Mai Quyen Hoang, Man Quan Nguyen, Thi Thu Nga Vu, G. Teyssedre, Séverine Le Roy. Modelling the impact of electrode roughness on net charge density in polyethylene. Journal of Physics D: Applied Physics, 2021, 10.1088/1361-6463/abfc8a . hal-03212528

\section{HAL Id: hal-03212528 \\ https://hal.science/hal-03212528}

Submitted on 28 Sep 2021

HAL is a multi-disciplinary open access archive for the deposit and dissemination of scientific research documents, whether they are published or not. The documents may come from teaching and research institutions in France or abroad, or from public or private research centers.
L'archive ouverte pluridisciplinaire HAL, est destinée au dépôt et à la diffusion de documents scientifiques de niveau recherche, publiés ou non, émanant des établissements d'enseignement et de recherche français ou étrangers, des laboratoires publics ou privés. 


\title{
Modelling the impact of electrode roughness on net charge density in polyethylene
}

\author{
M.Q. Hoang ${ }^{1}$, M.Q. Nguyen ${ }^{1}$, T.T.N. Vu ${ }^{2}$, G. Teyssedre ${ }^{3}$ and S. Le Roy ${ }^{3}$ \\ ${ }^{1}$ Faculty of Electrical Engineering, Hanoi University of Industry, Hanoi, Vietnam \\ ${ }^{2}$ Faculty of Electrical Engineering, Electric Power University, Hanoi, Vietnam \\ ${ }^{3}$ LAPLACE, Université de Toulouse, CNRS, INPT, UPS, Toulouse, France \\ E-mail: severine.leroy@laplace.univ-tlse.fr
}

\begin{abstract}
Predicting the electric field distribution under dc stress within polymeric insulations remains a challenge, as space charge behaviour is still difficult to understand in these materials. Charge generation is often thought to arise from injection at the electrodes. Hence, surface roughness should be taken into account, as it strengthens the electric field locally and therefore promotes charge generation at some points. A charge transport model has been developed in $2 \mathrm{D}$ to account for surface roughness. The model is first validated with the help of previous results, obtained with a one dimensional charge transport model. Then, with simple shapes accounting for roughness, the simulated results show that surface roughness has a significant impact on the net space charge behaviour. The impact of shape, and size of protusions is presented, as well as a more realistic case were a large surface of the electrode is considered as rough.
\end{abstract}

Keywords: charge transport model, space charge, multidimensional, roughness, injection, polymeric insulation

\section{Introduction}

For dc stress applications, challenges in the field of polymeric insulations are related to the prediction of electric field distribution within the material, and hence to the prediction of space charge accumulation. Charges, generated from injection at the electrode or from dissociation inside the material can lead to local field enhancement, and potentially to early electrical failure. To account for such behaviour, charge transport models have been developed since two decades, mostly on polyethylene based materials [1-4]. However, even if low density polyethylene (LDPE) is the simplest polymer in its structure $\left(-\mathrm{CH}_{2}-\mathrm{CH}_{2}-\right)$, the physical processes linked to charge generation and accumulation remain difficult to grasp, and hence difficult to model. One of the challenges arises from charge generation, injection being the dominant physical process providing charges inside the LDPE material. Experimental [5-7] and theoretical [7-9] researches have been published in the litterature. These researches have focussed on injection barrier height [7-10], on contact charges at the interfaces [11], on material structure in terms of energy states (i.e. traps) at the interfaces, and lastly on surface roughness $[12,13]$. This last point is of importance, as the shape of the surface where the voltage is applied is directly related to electric field enhancement. As most of the physical processes are field dependent, a variation of the surface roughness could lead to totally different macroscopic variables such as space charge or current. In the present study, we first present the 2D charge transport model developed for the case of surface roughness modelling, and validate it with previously published simulation results using a 1D model. We then present the impact of different roughness shapes on space charge density. At last, the present paper proposes to further understand the possible relation between surface roughness 
and fast charge injection, a specific behaviour observed in the literature for several insulating polymers, among them LDPE.

\section{Model description}

A bipolar charge transport model, already published in the literature [2], has been developed in two dimensions using a commercial finite element modelling (FEM) software. In the present paper, the sample considered is a low density polyethylene (LDPE) of thickness $150 \mu \mathrm{m}$, and has a width of $45 \mu \mathrm{m}$. The sample is considered as homogeneous in the third dimension. The experimental protocol consists in the application of an electric field of $40 \mathrm{kV} / \mathrm{mm}$ during 1 hour, at $25^{\circ} \mathrm{C}$. An applied voltage $(6 \mathrm{kV})$ is set at the anode, corresponding to the top electrode, while the cathode, which is the bottom electrode, is grounded. Figure 1 presents the overall sample and applied voltage configuration.

The physical hypotheses [2] taken into account in the model are presented schematically in Figure 2, and are the following:

- Only electronic carriers (i.e. electrons and holes) are considered

- Charge generation arises only from injection of electronic carriers at each electrode, depending on the sign of the applied electric field

- Electronic charges have a constant effective mobility, which already takes into account the possible trapping and detrapping into shallow traps

- Electronic charges can be trapped into a single level of deep traps for each species, using a constant trapping coefficient

- Trapped charges can detrap, with a thermally assisted physical process

- Recombination of charges of opposite sign is also taken into account, with constant parameters.

The equations to solve are of the form:

$\frac{\partial n_{a}}{\partial t}+\nabla \cdot\left( \pm n_{a} \mu_{a} E-D_{a} \nabla n_{a}\right)=s_{a}$

$$
\nabla \cdot\left(\varepsilon_{0} \varepsilon_{r} E\right)=\rho
$$

Where $\mathrm{n}_{\mathrm{a}}$ is the charge density $\left(\mathrm{C} / \mathrm{m}^{3}\right)$, and a refers to the charge carrier, being electron (e) or hole $(\mathrm{h})$, mobile $(\mu)$ or trapped ( $\mathrm{t}) . \mathrm{t}$ is the time, $\mu_{\mathrm{a}}$ the mobility $\left(\mathrm{m}^{2} / \mathrm{V} / \mathrm{s}\right)$, for

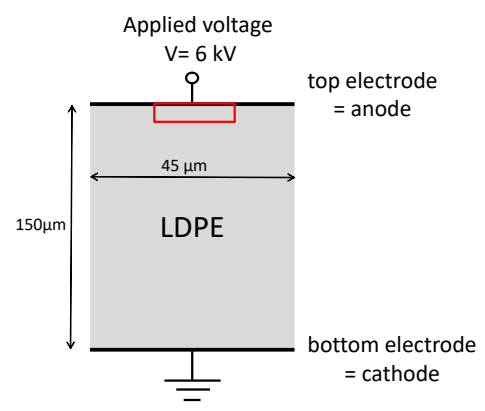

Figure 1. Schematic representation of the LDPE sample considered and the applied voltage configuration. eachcharge carrier, $\mathrm{E}$ the electric field $(\mathrm{V} / \mathrm{m}), \varepsilon_{0}$ is the vacuumpermittivity, and $\varepsilon_{r}$ the relative permittivity of the material and $\rho$ the net charge density $\left(\mathrm{C} / \mathrm{m}^{3}\right)$. $\mathrm{D}_{\mathrm{a}}$ refers to the diffusion coefficient, and is of the form, following the Einstein relation:

$$
D_{a}=\frac{k_{B} T}{e} \mu_{a}
$$

Where $\mathrm{k}_{\mathrm{B}}$ is the Boltzmann's constant, e the elementary charge and $\mathrm{T}$ is the temperature $(\mathrm{K})$.

$\mathrm{S}_{\mathrm{a}}$ are the source terms, reflecting all the physical processes not linked to transport. An example of source term for mobile electrons is given in:

$$
s_{e \mu}=-B_{e} n_{e \mu}\left(1-\frac{n_{e t}}{N_{0 e t}}\right)+v n_{e t} \exp \left(\frac{-e w_{t r a}}{k_{B} T}\right)-
$$

$S_{1} n_{e \mu} n_{h t}-S_{3} n_{e \mu} n_{h \mu}$

Here, $B_{e}$ is the trapping coefficient $\left(\mathrm{s}^{-1}\right), \mathrm{N}_{0 e t}$ the trap density for electrons, $v$ the attempt to escape frequency $\left(\mathrm{s}^{-1}\right), \mathrm{w}_{\text {tra }}$ is the detrapping barrier height for electrons $(\mathrm{eV}) . \mathrm{S}_{1}$ and $\mathrm{S}_{3}$ are the recombination coefficients $\left(\mathrm{m}^{3} / \mathrm{C} / \mathrm{s}\right)$. The same kind of equation would hold for trapped electrons and mobile and trapped holes, and can be found in [2].

Charge generation is only due to injection of carriers at each electrode, and follows a modified Schottky law :

$j_{\text {Schott }}(A, C)=A T^{2} \exp \left(\frac{-e w_{a i}}{k_{B} T}\right)\left[\exp \left(\frac{e}{k_{B} T} \sqrt{\frac{e E_{a, c}}{4 \pi \varepsilon_{0} \varepsilon_{r}}}\right)-1\right](5)$

Where A is the Richardson's constant, $\mathrm{w}_{\mathrm{ai}}$ is the injection barrier height, for electrons or holes $(\mathrm{eV})$, and the coordinate $\mathrm{A}$ or $\mathrm{C}$ refers respectively to the anode or to the cathode. No extraction barriers are taken into account at the electrodes, so the extraction fluxes for holes at the cathode and for electrons at the anode follow the transport equation, of the form:

$j_{a, e x t}= \pm n_{a} \mu_{a} E-D_{a} \nabla n_{a}$

All the variables are function of space and time, even if equations (1-5) do not reflect this, for sake of simplicity.

The model has been applied to a LDPE, for which optimized parameters have already been published in the literature for a one dimension model [2], and are listed in Table 1. The model, developed with COMSOL Multiphysics ${ }^{\circledR}$ uses the Transport

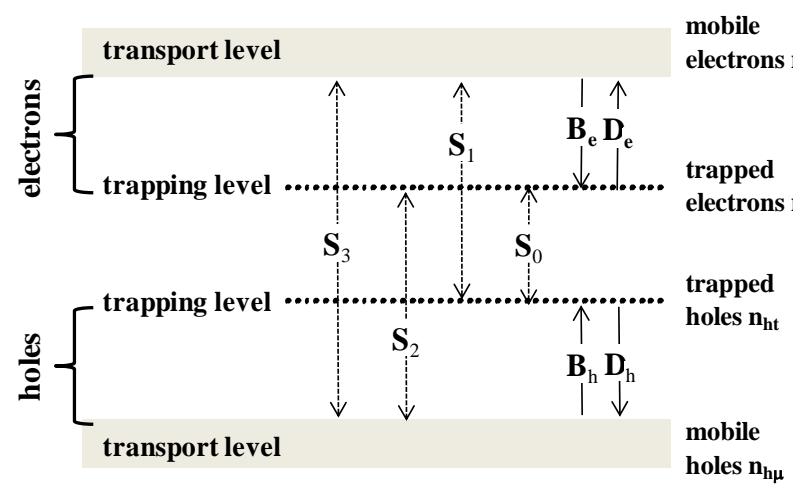

Figure 2. Schematic representation of the two-levels transport model. Conduction is by free charges in the transport levels, associated with a constant mobility. 
Table 1. Parameters used for the simulations

\begin{tabular}{|c|c|c|}
\hline Symbol & value & units \\
\hline $\begin{array}{l}\text { Trapping coefficients } \\
\mathrm{B}_{\mathrm{e}} \text { electrons } \\
\mathrm{B}_{\mathrm{h}} \text { holes }\end{array}$ & $\begin{array}{l}\text { 1. } 10^{-1} \\
\text { 2. } 10^{-1}\end{array}$ & $\begin{array}{l}\mathrm{s}^{-1} \\
\mathrm{~s}^{-1} \\
\end{array}$ \\
\hline $\begin{array}{l}\text { Mobility for } x \text { and } z \text { axis } \\
\mu_{\mathrm{e}} \text { for electrons } \\
\mu_{\mathrm{h}} \text { for holes }\end{array}$ & $\begin{array}{l}\text { 1. } 10^{-14} \\
\text { 2. } 10^{-13}\end{array}$ & $\begin{array}{l}\mathrm{m}^{2} / \mathrm{V} / \mathrm{s} \\
\mathrm{m}^{2} / \mathrm{V} / \mathrm{s}\end{array}$ \\
\hline $\begin{array}{l}\text { Trap densities } \\
\mathrm{N}_{\text {oet }} \text { for electrons } \\
\mathrm{N}_{\text {oht }} \text { for holes }\end{array}$ & $\begin{array}{l}100 \\
100 \\
\end{array}$ & $\begin{array}{l}\text { C. } \mathrm{m}^{-3} \\
\text { C. } \mathrm{m}^{-3}\end{array}$ \\
\hline $\begin{array}{l}\text { Injection barrier heights } \\
\mathrm{w}_{\mathrm{ei}} \text { for electrons } \\
\mathrm{w}_{\mathrm{hi}} \text { for holes }\end{array}$ & $\begin{array}{l}1.27 \\
1.16 \\
\end{array}$ & $\begin{array}{l}\mathrm{eV} \\
\mathrm{eV}\end{array}$ \\
\hline $\begin{array}{l}\text { Recombination coefficients } \\
S_{0}, S_{1} \text { and } S_{2} \\
S_{3}\end{array}$ & $\begin{array}{l}\text { 4. } 10^{-3} \\
0 \\
\end{array}$ & $\begin{array}{l}\mathrm{m}^{3} / \mathrm{C} / \mathrm{s} \\
\mathrm{m}^{3} / \mathrm{C} / \mathrm{s}\end{array}$ \\
\hline Relative permittivity & 2.3 & \\
\hline $\begin{array}{l}\text { Detrapping barrier heights } \\
\mathrm{w}_{\text {tre }} \text { for electrons } \\
\mathrm{w}_{\text {trh }} \text { for holes }\end{array}$ & $\begin{array}{l}0.96 \\
0.99\end{array}$ & $\begin{array}{l}\mathrm{eV} \\
\mathrm{eV}\end{array}$ \\
\hline
\end{tabular}

of Diluted Species (TDS) module to solve the continuity equation for each kind of carrier (4).

The advantage of this module is that it already includes solutions (i.e. stabilization) to prevent oscillations. The Poisson equation module is used to couple these equations to the Poisson's equation. Backward Differentiation Formula solver is used for the time integration (maximum order 2, and minimum order 1). A zero flux is set as boundary condition on the left and right sides. Before voltage application, no charges are present in the material.

\section{Validation of the 2D model}

Simulation results using the 2D model, developed with a FEM software have been compared to a 1D Fortran model, developed using the finite volume method [14], in order to validate the $2 \mathrm{D}$ model as regards the number of cells, and the numerical schemes implicitely available in the TDS module. Figure $3 \mathrm{a}$ presents the electric field profile while Figure $3 \mathrm{~b}$ ) presents the net charge density as a function of the depth in the sample for both models and for different simulation times. The simulated electric fields and net charge density results are comparable whatever the simulation time. The small difference observed between the results can be due to the numerical schemes used, that can give rise to more diffusion in the case of the FEM model. The 2D FEM model developed, with the chosen numerical schemes, and the meshing, is then validated and will be used for further development.

\section{Impact of interface roughness on the space charge behaviour}

\subsection{Impact of the roughness shape}

Simulations have been performed with the 2D model, in order to observe the impact of surface roughness on the macroscopic space charge behaviour. Previous studies on the impact of
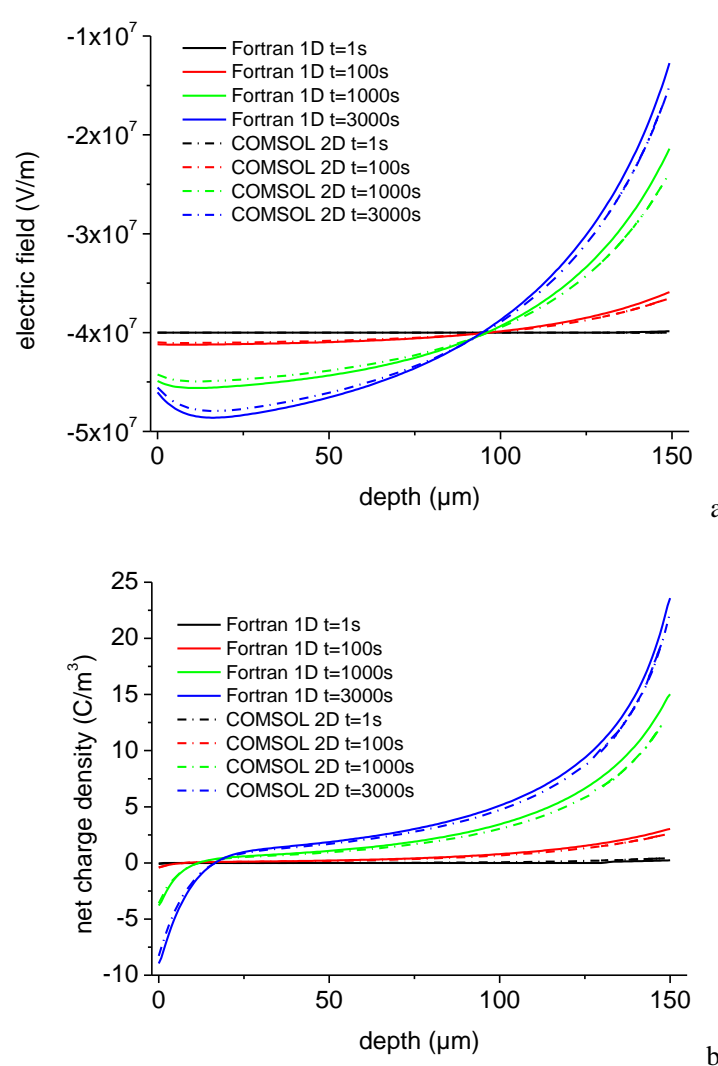

b)

Figure 3. a) Electric field and b) net charge density as a function of depth in the sample for a 1D model developed resolved in Fortran and a 2D model developed using the FEM method.

surface roughness on electric field distribution [6,7] have shown that concave defects forming protrusions on the electrode enhance the electric field to a large extent. The field enhancement factor (FEF), i.e. the ratio between local electric field and applied one, is greater than 1 in this case [6]. On the contrary, the local electric field is reduced with convex defects. Hence, to account as simply as possible for roughness in this paper, only concave shapes have been studied, with different geometries from left to right: a semi-circle, a sinus wave (width $=1 \mu \mathrm{m}$ ) and a semi-ellipse with a width of $1.4 \mu \mathrm{m}$

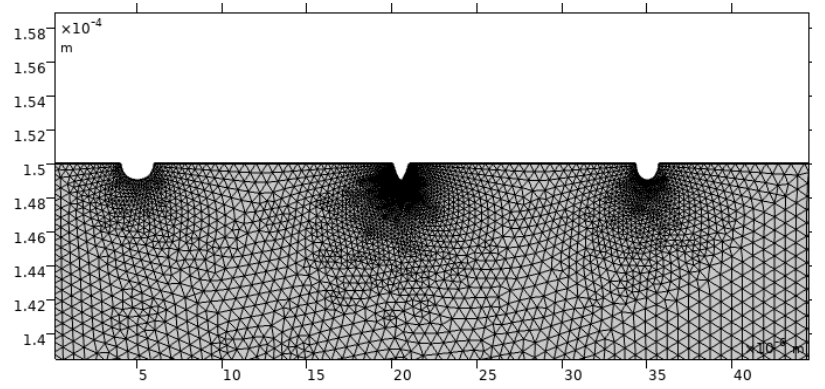

Figure 4. Shapes and meshing close to each protrusion: left: semi-circle, centre: sine, right: semi-ellipse. Zoom of the surface of the simulated sample. 
(Figure 4). Each defect has a height of $1 \mu \mathrm{m}$. These different shapes, accounting for roughness, are positioned so that there is no impact of each shape on the other one, and have been set at the anode only (i.e. top electrode), while the cathode remains smooth. The sizes of protrusions are consistent with measured surface roughness features [7]. Voltage is set on the sample surface, i.e. no air gap is considered on the roughness zones. The boundary conditions remain the same as in the case of a $2 \mathrm{D}$ model with no roughness.

Figure 5 presents the 2D net charge density as a function of space for this case study, and for a charging time of $20 \mathrm{~s}$ (Figure 5a) and 200s (Figure 5b). Charge injection at the anode is highly enhanced where protrusions are located, with a maximum at the cavity tip. This enhanced injection, of the Schottky type, is directly linked to the local electric field, which is higher (in absolute value) that the applied electric field at the defect tip (Figure 6). As an example for 20s, the electric field at the tip of the semi-circle is of the order of 75 $\mathrm{kV} / \mathrm{mm}$, it is $90 \mathrm{kV} / \mathrm{mm}$ for the semi-ellipse and around 150 $\mathrm{kV} / \mathrm{mm}$ for the sinus shape. Hence, a large amount of positive charges is generated next to each protrusion. On the contrary, the geometric electric field is lower at each junction between the defect and the surface (Figure 6). The electric field variation at the top electrode due to roughness does not completely explain all the observed processes. As an example after 20s (Figure 5a) positive charges at the vertical of a protrusion have mostly crossed the material, i.e. $150 \mu \mathrm{m}$. However, the impact of the geometry on the electric field value is effective only on a few $\mu \mathrm{m}$ from the surface [6] and cannot completely explain the fast positive charges

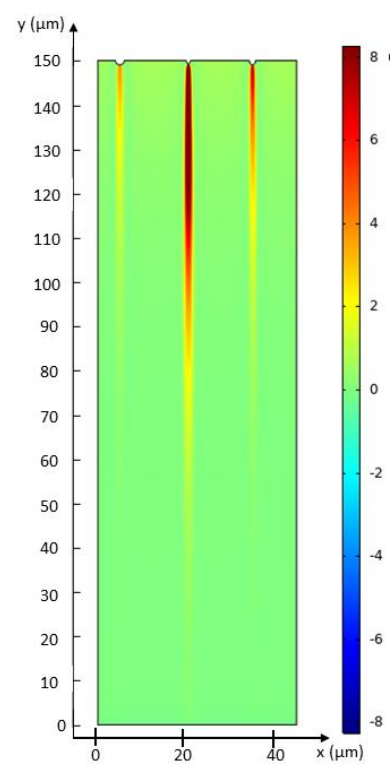

a)

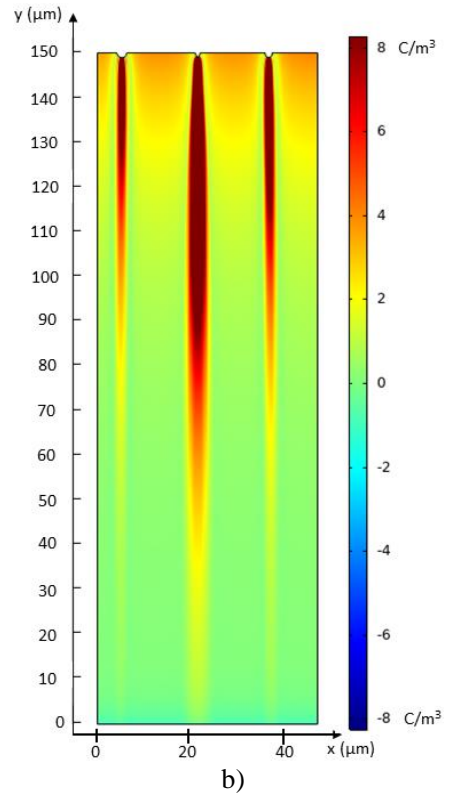

b)
Figure 5. Net charge density in the LDPE sample, with different protrusion shapes at the top electrode, for a) $t=20 s$, and b) $t=200 \mathrm{~s}$.

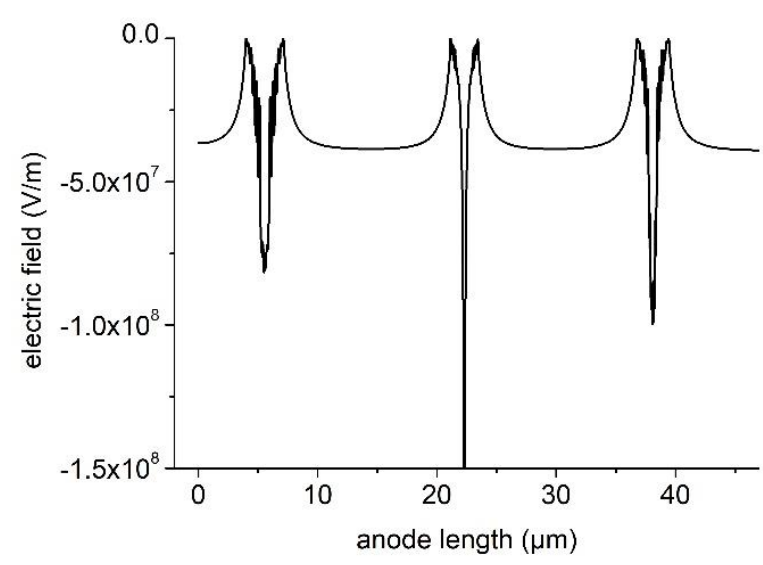

Figure 6. Geometric electric field along the anode, with protrusions having the form of a semi-circle, a sinus and a semi-ellipse. $t=20$ s.

penetration within the sample. Positive charges, injected to a large amount at each cavity, quickly decrease the electric field in this zone, as observed on Figure 7. The electric field is however increased in the volume of LDPE ahead of the charge cloud, leading to an increased velocity of positive charges. For a time of 200s, the maximal electric field is located at the vicinity of the bottom electrode, and is of the order of 45-50 $\mathrm{kV} / \mathrm{mm}$ at the vertical of each protrusion. It increases slightly compared to the case where no roughness is considered. This in return enhances the negative charge injection at the cathode, becoming inhomogeneous even if the surface is smooth. In the present paper, the mobility is constant. Taking an electric field dependent mobility, such as one of the hopping type, would enhance even more this behaviour. The other process responsible of the fast charge penetration is diffusion, which is taken into account in the model (see equation (1)). A large amount of positive charges is present at the top electrode, while no positive charges are initially present at the bottom electrode. The concentration gradient enables positive charges to diffuse from the top to the bottom electrode, in the region

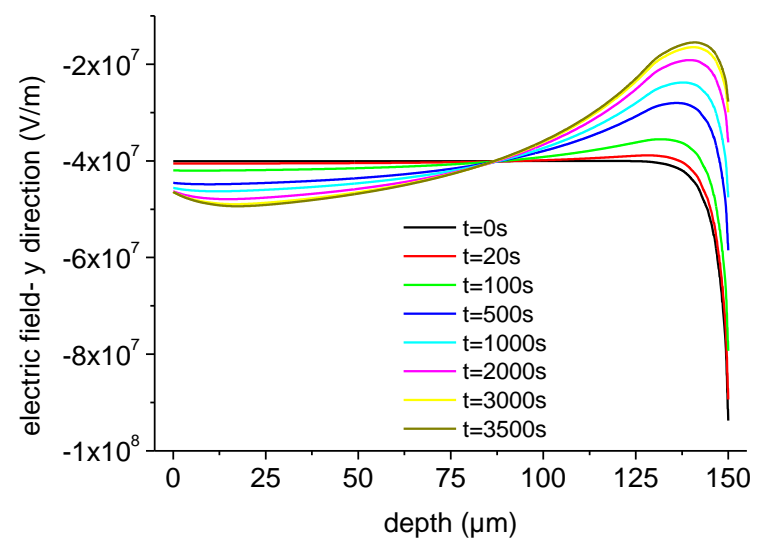

Figure 7. Electric field (y direction) as a function of the depth in the sample, for different times under applied voltage. Line cut taken at the vertical of the semi-ellipse tip. 
where a high concentration exists. For a time of 200s (Figure $5 b)$, positive charge injection is also visible all along the top electrode, with a lower injection rate compared to the roughness zones.

A further analysis has been performed on these simulations. Experimentally, space charge measurements realized with the Pulsed Electro-Acoustic method (PEA), for example, integrate the response over a surface corresponding to that of the piezoelectric sensor, leading to a net charge density as a function of the sample thickness for each measurement time. Such result can be obtained with the 2D simulation by integrating the net charge density along the length of sample ( $x$ axis) shown in Figure 5, for each simulation time. This analysis has been performed for the previous simulation, for the case where a roughness exists (by integrating along the $\mathrm{x}$ axis where a semi-circle, a sinus and a semi-ellipse exists) and for the case where no defect is taken into account. The integrated net charge density as a function of depth in the sample is presented in Figure 8 for different times under applied voltage, for both cases. The top electrode is located on the right side. The global behaviour is comparable for both cases study. For times shorter than 3500s, the positive charge, observed in most of the sample, has a higher value when roughness is considered. This is an expected behaviour considering the high injection associated to each protrusion. Next to the top electrode however, there is a decrease of the net charge density, being still positive, but lower when roughness is considered. One could think that the lowering of charge injection in this zone due to the presence of homocharges would not be visible as the ratio roughness zones/no roughness zones is small. This is however not the case as positive charge decrease is clearly visible on Figure 8. This particular behaviour should be enhanced for more realistic cases where all the surface of the electrode is rough.

\subsection{Impact of the defect size}

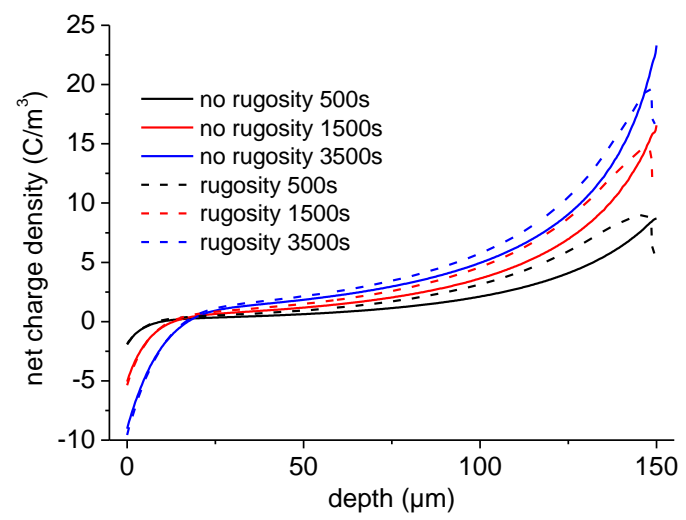

Figure 8. Integrated net charge density along sample length (i.e. x-axis) as a function of the depth in the sample, for different times under applied voltage. Anode on the right side.
Simulations have been performed to understand the impact of the height and width of the defect on the overall space charge behaviour. Roughness is accounted for with ellipses, characterized by their horizontal radius a (defect half-width) and vertical radius $b$ (defect height), with, from protrusion (1) to (4), presented on Figure 9: (1) $a=150 \mathrm{~nm} / \mathrm{b}=300 \mathrm{~nm},(2)$ $\mathrm{a}=300 \mathrm{~nm} / \mathrm{b}=600 \mathrm{~nm},(3) \mathrm{a}=400 \mathrm{~nm} / \mathrm{b}=1 \mu \mathrm{m}$, and (4) $\mathrm{a}=700$ $\mathrm{nm} / \mathrm{b}=1 \mu \mathrm{m}$. Semi-ellipse number (4) is the one that has been modelled in the previous section. Figure 9 presents the net charge density as a function of space for a time of 20 s and a time of 200s. The global behaviour is the one that has been observed in the previous section, i.e. an enhanced positive charge injection where protrusions exist, and a faster penetration of positive charges within the bulk due to field strengthening. This behaviour is directly linked to the width and height of the defect, and follows the initial geometric electric field distribution. A high ratio b/a leads to the highest electric field at the tip of the ellipse. On the contrary, a low ratio leads to a smaller FEF. The protrusion height also impacts on the spreading of the high electric field zone at the cavity location. The overall impact on the integrated net charge density (i.e. as could be probed by space charge measurement) is approximately the same as what has been observed for different roughness shapes.

\subsection{Case of a rough electrode}

Simulations have been performed in the case where the top electrode has a large number of protrusions, traducing a rough electrode on a length of around $10 \mu \mathrm{m}$. Figure 10 presents the simulated roughness, consisting in cavities of different shapes and sizes in LDPE. The longest defect is $800 \mathrm{~nm}$, the smallest

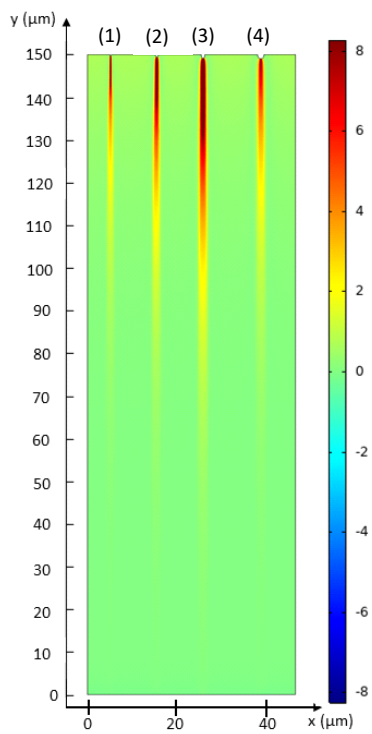

a)

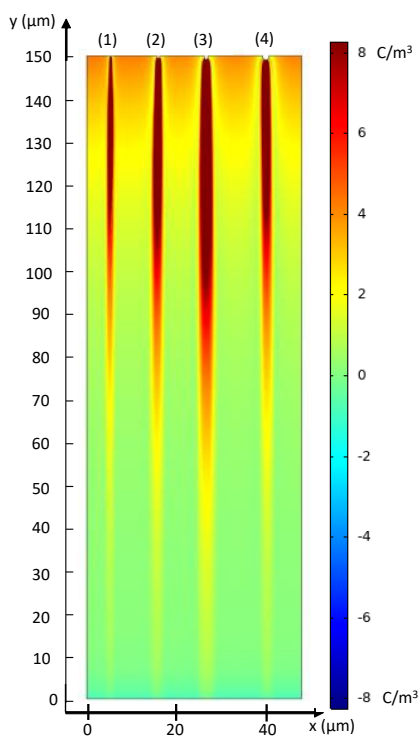

b)
Figure 9. Net charge density as a function of space in a LDPE sample, with a top electrode containing different semi-ellipse sizes $(\mathrm{a} / \mathrm{b})$. Protrusion (1): $150 \mathrm{~nm} / 300 \mathrm{~nm}$; (2) 300nm/600nm; (3) $400 \mathrm{~nm} / 1 \mu \mathrm{m}$; (4) $700 \mathrm{~nm} / 1 \mu \mathrm{m}$, for a time of a) $\mathrm{t}=20 \mathrm{~s}$, and b) $\mathrm{t}=200 \mathrm{~s}$. 


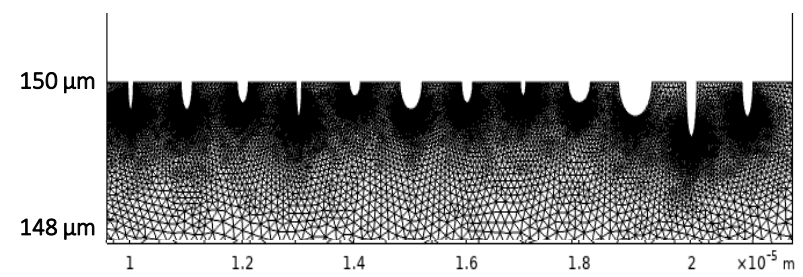

Figure 10. Zoom of the rough zone on the top electrode surface.

one $200 \mathrm{~nm}$. The width of the ellipses varies between $50 \mathrm{~nm}$ and $400 \mathrm{~nm}$. It is to note that the size of a protrusion accounting for roughness is of the order of hundreds of $\mathrm{nm}$, while the sample thickness is $150 \mu \mathrm{m}$. The meshing needs then to be refined as much as possible, which increases the simulation time. Simulations have been performed here for a time under applied voltage $(6 \mathrm{kV})$ of $1000 \mathrm{~s}$, which enables observing specific behaviour associated to surface roughness. The simulated results are presented in a way to be compared to real space charge measurements. Hence, the net charge density is integrated over the full length of the sample (x-axis), and is then plotted in a surface graph as a function of sample depth and time. Figure 11a presents the simulated results for the case of a rough electrode, as modelled by Figure 10, and is compared to the case where no rugosity exists, i.e. Figure $11 \mathrm{~b}$. It is to note that influence charges, normally observed on each electrode in space charge measurements such as PEA, and arising from capacitive charges + image charges of charges 1 ocated inside the bulk, have not been added to the cartography. These influence charges generally prevent observing the physical processes at play close to the electrodes. The behaviour is globally the same for the two cases, i.e. injection of positive charges that cross the sample, and slow injection of negative charges. Differences are also noticeable. Although only a fourth of the surface is rough (around $10 \mu \mathrm{m}$ over a length of $45 \mu \mathrm{m}$ ), the impact on the net charge density is highly visible. In the case of a rough electrode (Figure 11a), positive charges penetrate faster, and with a higher density inside the dielectric. This behaviour is attributed to the presence of roughness at the top electrode, as described in the previous sections. At the end of the polarization step (1000s), the positive charge density is higher in the case of a rough electrode compared to a smooth one. An increase of the charge density has also been observed experimentally [6] for different surface roughnesses, for low to moderate applied electric fields for polyethylene. Moreover, the fast appearance of positive charges soon after voltage application has also been observed experimentally for LDPE [18]. Although it was thought that these charges arise from injection at the electrode, charge penetration could not be attributed to 'simple' electric field driven injection and mobility processes. Hence, the present simulations show that this fast penetration of injected charges could be link to a rough electrode surface. This could also explain why this

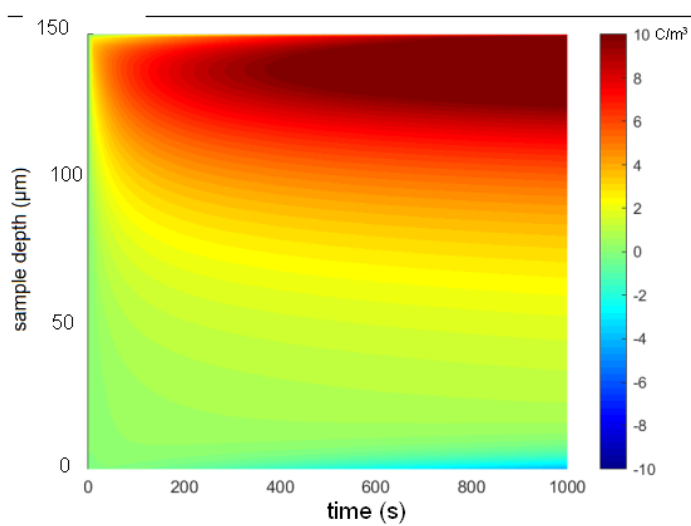

a)

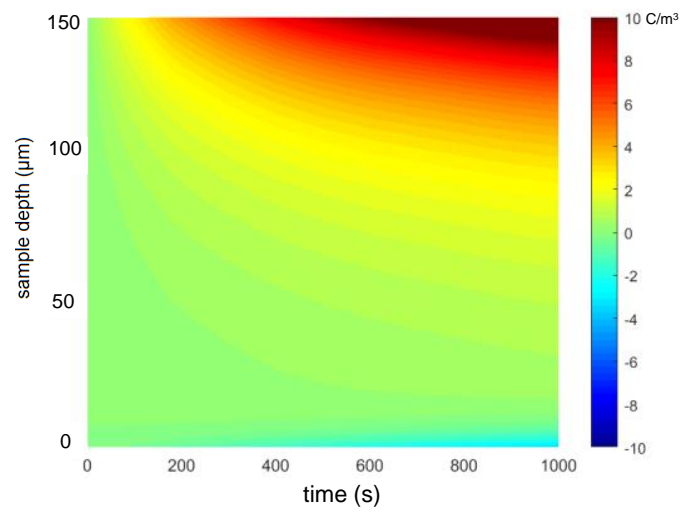

b)

Figure 11. Net charge density cartography as a function of time and depth in the sample, for a) a rough top electrode as proposed in Figure 9, an b) a smooth top electrode. Horizontal axis: time in $\mathrm{s}$. The colour scale provides charge density in $\mathrm{C} / \mathrm{m}^{3}$.

phenomenon of fast charge penetration is not always observed experimentally, even with the same kind of LDPE, and the same manufacturing process. A small change in the roughness (due to the mold as an example) will give rise to a high variation in the roughness and hence in charge penetration.

Negative charge injection is also slightly enhanced as a consequence of field strengthening ahead of the positive charge clouds produced by protrusions. Another difference between smooth and rough electrode is the amount of positive charges close to the top electrode, which is decreasing for a rough electrode. Positive charges, being injected in a large amount, decrease the electric field close to the top electrode, where roughness exists. This in turn will lower further injection of positive charges (as in Figure 8). This is observable particularly for times between some seconds and 400s. This could not be observed if influence charges where added to the net charge density. This behaviour (i.e. the decrease of the net charge density at the vicinity of the electrode) could also take part to the peculiar 'charge front' or 'charge packet' behaviour, often encountered for LDPE, but not yet fully understood [15]. Different hypotheses have been put forward to explain these effects such as field enhanced injection [15], negative differential mobility [16], contact charges [11] or even variation of crystallinity [5]. The 
modelling carried out here could help in unravelling this peculiar process.

\section{Conclusions}

A bipolar charge transport model has been developped in two dimensions in order to account for surface roughness effects into charge injection processes. The model has first been validated as regards previous results obtained with a one dimension finite volume method model. It has then evolved to account for surface roughness. Even if the simulated roughness is simple in its definition (i.e. circular, elliptic or sinusoidal shapes reflecting protusions of the electrode), it enables observing the impact of its presence on the net charge density. The ratio b/a axis of the elliptic protrusion shape has a clear impact on the net charge density: the higher the ratio, the higher the geometric electric field, and the higher the charge injection. When roughness is accounted for, charge injection is enhanced at the roughness location, and charge penetration into the dielectric bulk is also fasten, due to electric field redistribution. This behaviour is observable even when integrating the net charge density over the sample width, as what is done during a space charge measurement. Roughness could be at the origin of fast charge injection as observed experimentally. The investigation needs however to be strengthened. The next step will be to work with real surface topography, to verify if this hypothesis still holds.

\section{Acknowledgements}

This research is partly funded by Vietnam National Foundation for Science and Technology Development (NAFOSTED) under grant number 103.02-2019.33.

\section{References}

[1] Alison JM and Hill RM 1994 J. Phys. D: Appl. Phys. 27, 12911299

[2] Le Roy S, Teyssedre G, Laurent C, Montanari GC and Palmieri F 2006 J. Phys. D: Appl. Phys. 39 1427-1436

[3] Xia J, Zhang Y, Zheng F, An A and Lei Q 2011 J. Appl. Phys. 109034101

[4] Hoang AT, Serdyuk YV and Gubanski S 2016 Polymers 8103

[5] Yuanxiang Z, Yunshan W, Ninghua W and Qinghua S $2009 \mathrm{~J}$. Phys.: Conf. Series 183012009

[6] Doedens E, Jarvid EM, Guffond R and Serdyuk YV 2020 Energies 132005

[7] Taleb M, Teyssedre G and Le Roy S 2009 Proc. IEEE Conf. on Electrical Insulation and Dielectric Phenomena, pp. 112-115

[8] El-Shahat M, Huzayyin A and Anis H 2018 IEEE Trans. Dielectr. Electr. Insul. 25 2178-2182

[9] Huzayyin A, Boggs S and Ramprasad R 2011 Proc. IEEE Conf. on Electrical Insulation and Dielectric Phenomena, pp. 800-803

[10] Wang W, Takada T, Tanaka Y and Li ST 2017 IEEE Trans. Dielectr. Electr. Insul. 24 2599-2606

[11] Le Roy S, Villeneuve-Faure C, Chang JH and Huzayyin A 2016 Proc. IEEE Int. Conference on Dielectrics, pp. 897-900
[12] Taleb M, Teyssèdre G, Le Roy S and Laurent C 2013 IEEE Trans. Dielectr. Electr. Insul. 20 311-320

[13] Doedens E, Jarvid EM, Guffond R and Serdyuk YV 2020 Energies 131750

[14] Le Roy S, Teyssedre G and Laurent C 2006 IEEE Trans. Dielectr. Electr. Insul. 13 239-246

[15] Hozumi N, Suzuki H, Okamoto T, Watanabe K and Watanabe A 1994 IEEE Trans. Diel. Elect. Insul. 1, pp. 1068-1076

[16] Chen G and Zhao J 2011 J. Phys. D: Appl. Phys. 44212001

[17] Fukuma M, Fukunaga K and Laurent C 2006 Appl. Phys. Lett. 88253110

[18] Tanaka Y. 2018 IEEE Int. Conf. on the Properties and Applications of Dielectric Materials pp. 1-10 